\title{
АВТОМАТИЗАЦИЯ ВЗАИМОДЕЙСТВИЯ РЕГИОНАЛЬНЫХ НАВИГАЦИОННО-ИНФОРМАЦИОННЫХ СИСТЕМ ПРИ МОНИТОРИНГЕ ТРАНСПОРТНЫХ СРЕДСТВ
}

\author{
Л. И. Остринская ${ }^{\star}$ С. Ю. Пестова ${ }^{\star}$, А. В. Козлова ${ }^{\star}$, А. А. Ключенко ${ }^{\star \star}$ \\ ${ }^{*}$ Сибирский государственный автомобильно-дорожный университет (СибАДИ) \\ ** Главное управление информационных технологий и связи Омской области
}

Поступила в редакцию 19.11.2018 г.

\begin{abstract}
Аннотация. Рассматриваются проблемы организации взаимодействия региональных навигационно-информационных систем. Разработка данных систем является составляющей региональных программ по обеспечению безопасности пассажирских и грузоперевозок. Анализ процессов, связанных с мониторингом транспортных средств, позволил выявить проблемы при взаимодействии региональных навигационно-информационных систем разных регионов. В статье представлена разработка модуля взаимодействия региональных навигационно-информационных систем при мониторинге и обмене информации о транспортных средствах, обеспечивающий автоматизацию данного процесса.

Ключевые слова: региональная навигационно-информационная система, информационное взаимодействие, автоматизация, разработка информационных систем.

Annotation. The problems of organizing the interaction of regional navigation information systems are considered. The development of these systems is a component of regional programs to ensure the safety of passenger and freight traffic. Analysis of the processes associated with the monitoring of vehicles, allowed to identify problems in the interaction of regional navigation and information systems in different regions. The article presents the development of a module for the interaction of regional navigation information systems in the monitoring and exchange of information about vehicles, which provides automation of this process.

Keywords: regional navigation and information system, information interaction, automation, development of information systems.
\end{abstract}

\section{ВВЕДЕНИЕ}

Вопросы безопасности на дорогах одна из важных составляющих современного общества, которое использует информационные технологии для мониторинга, контроля и анализа различных процессов. Так, начиная с 2012 года, были определены обязательное оснащение транспортных средств спутниковой аппаратурой, требования к аппаратуре и к протоколам обмена данными. Предполагалось, что разрабатываемая федеральная автоматизированная система Ространснадзора позволит обеспечивать навигационный контроль за перевозками опасных грузов и пассажиров. Аккредитованные телематиче-

() Остринская Л. И., Пестова С. Ю., Козлова А. В., Ключенко А. А., 2018 ские региональные операторы передавали бы навигационные данные от транспорта, оснащенного аппаратурой спутниковой навигации, в Ространснадзор. Для решения данной задачи регионам была поставлена задача создания Региональных навигационно-информационных систем (РНИС) в транспортных коридорах, «Запад-Восток» и «Север-Юг».

В каждом регионе была утверждена региональная программа, которая содержит мероприятия по введению в постоянную эксплуатацию региональных навигационно-информационных систем, удовлетворяющих требованиям (в том числе по программному обеспечению), установленных Министерством транспорта Российской Федерации.

Целями РНИС являются: повышение эффективности государственного (муниципального) управления и реализации кон- 
трольно-надзорных полномочий в транспортном комплексе на территории субъекта Российской Федерации; повышение уровня безопасности перевозок пассажиров, специальных и опасных грузов, тяжеловесных и крупногабаритных грузов за счет оперативности реагирования на чрезвычайные ситуации, а также на нарушения правил перевозки пассажиров и грузов.

Отмена Верховным судом приказа Министерства транспорта РФ «Об утверждении порядка оснащения транспортных средств, находящихся в эксплуатации...» привела к тому, что созданные региональные системы являются автономными, не связанными ни с системами других регионов, ни с федеральным центром. Вследствие этого процессы автоматизированного взаимодействия РНИС разных регионов требуют доработки. В частности, при передаче транспортного средства (TC) из одного региона в другой. Аспекты оптимизации и автоматизации данного процесса посредством проектирования и разработки модуля взаимодействия региональных навигационно-информационных систем для обеспечения безопасности пассажиров и грузоперевозок и являются целью исследования.

Анализируя научные исследования и практические разработки по различным аспектам (правовое, информационное, методическое обеспечение, алгоритмы обработки и протоколы обмена данных, доступ и хра- нение пространственных данных на основе единого регионального ГИС-сервера) разработки региональных навигационно-информационных систем на наземном транспорте были выявлены проблемы взаимодействия РНИС разных регионов при осуществлении диспетчерского контроля транспортных средств [1]. В частности, с подобными сложностями столкнулись в Псковской и Орловской областях $[2,3]$.

\section{Анализ предметной области}

Пункт 3 распоряжения Губернатора Омской области от 30 апреля 2015 года N 95-p «O государственной информационной системе Омской области «Региональная навигационно-информационная система Омской области» [4] определяет порядок размещения и использования информации в государственной информационной системе Омской области «Региональная навигационно-информационная система Омской области» - РНИС Омской области, функционирующей в непрерывном и круглосуточном режиме работы.

В процессе функционирования и использования РНИС Омской области информационное взаимодействие осуществляется между оператором РНИС Омской области (обеспечивает предоставление доступа к мониторинговой информации РНИС Омской области, табл. 1) и компаниями, которые занимаются перевозкой багажа, пассажиров, опасных,

Таблица 1

Мониторинговая информация РНИС

\begin{tabular}{|l|l|}
\hline \multicolumn{1}{|c|}{ Виды мониторинга } & \multicolumn{1}{|c|}{ Данные мониторинга } \\
\hline Режим наблюдения & 1) Скорость транспортных средств \\
в реальном времени & 2) Текущее состояние (на ходу или остановка) \\
\hline Отчеты & $\begin{array}{l}\text { 1) Безопасность дорожного движения (превышение скоростного ре- } \\
\text { жима; превышение скоростного режима на опасных участках) } \\
\text { 2) Статистика (количество рейсов; нахождение на стоянке или марш- } \\
\text { руте; интервалы движения; сводный отчет) } \\
\text { 3) Контроль (прохождение контрольных точек; факты «среза» марш- } \\
\text { рута; соблюдение расписания движения (обгон одним водителем дру- } \\
\text { гого водителя при движении от конечной до конечной) }\end{array}$ \\
\hline История движения & $\begin{array}{l}\text { 1) выгрузка маршрута следования } \\
\text { 2) количество рейсов } \\
\text { 3) среднее время рейса (для пассажирского маршрутного транспорта) }\end{array}$ \\
\hline
\end{tabular}




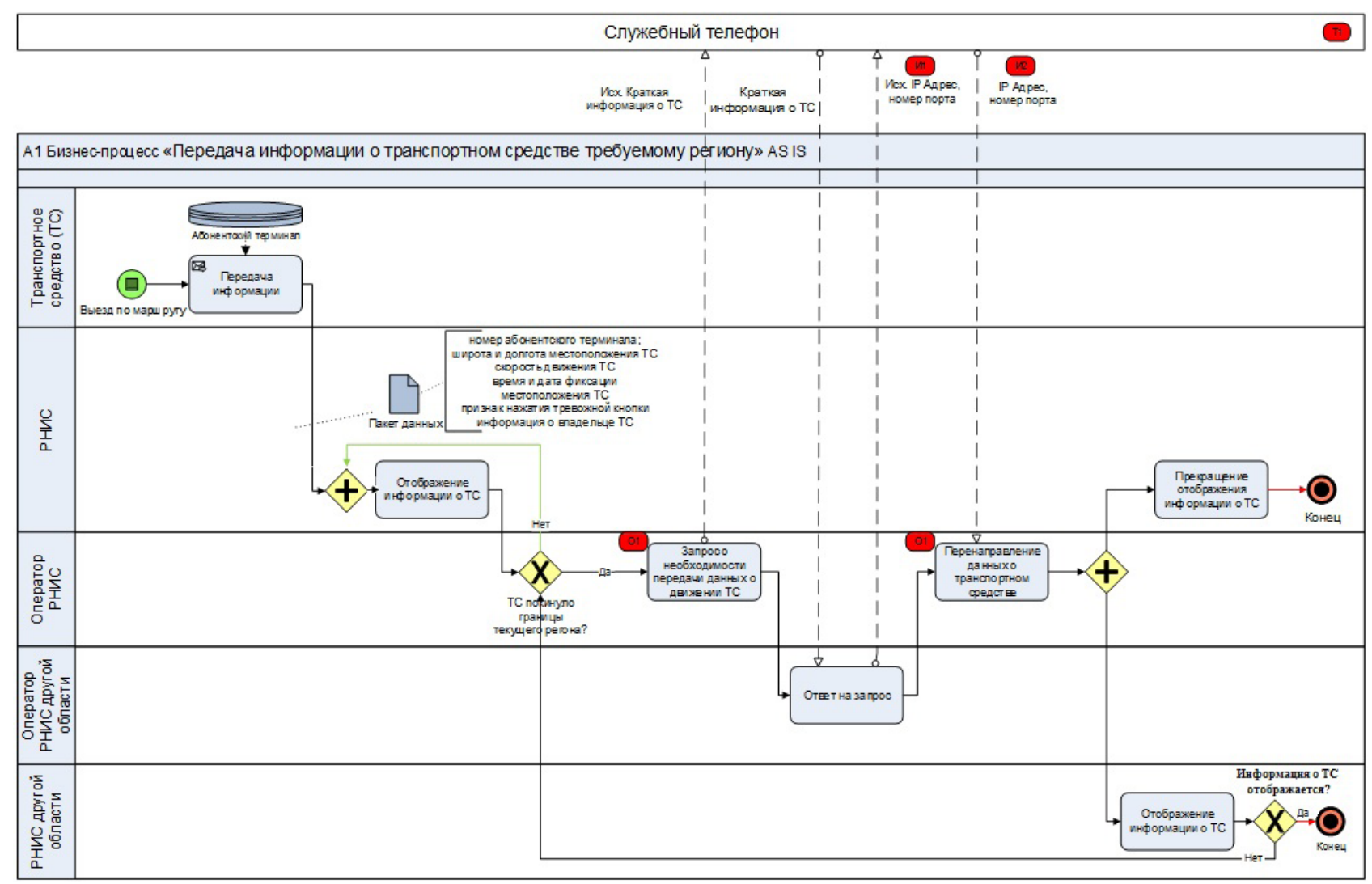

Рис. 1. Бизнес-прочесс «Передача данных о ТС требуемому региону» (AS IS)

крупногабаритных грузов и пр., а также органами власти, осуществляющими контроль и надзор с использованием РНИС $[5,6]$.

Анализируя работу операторов, удалось выявить некоторые недостатки системы. Например, РНИС разных областей могут обмениться информацией о транспортных средствах сложным и неудобным способом, занимающим некоторое количество времени. Бизнес-процесс «Передача данных о транспортном средстве требуемому региону», представлен на рис. 1.

Входными данными исследуемого процесса является пакет данных о транспортном средстве, включающий: номер абонентского терминала; признак нажатия тревожной кнопки; широта и долгота местоположения TC; время и дата фиксации местоположения TC; скорость движения ТC; IP адрес и номер порта. На выходе формируются данные о ТС для другого региона. Участниками процесса являются оператор РНИС, оператор РНИС другой области, РНИС, РНИС другой области.

В общем виде передача информации о транспортном средстве требуемому регио- ну состоит в: процессе сбора информации о ТC (собирается пакет данных в абонентском терминале для отправки на сервер); передаче информации на требуемый сервер; отображении информации в требуемой РНИС.

Анализ данного бизнес-процесса на предмет выявления узких мест позволил выделить различные уровни проблем, представленные в табл. 2.

Главной проблемой, в этой связи, видится отсутствие автоматизации процесса передачи данных и транспортном средстве другому региону.

Решить вопрос оптимизации можно несколькими способами:

1) автоматизировать процесс, который приведет к значительному уменьшению временных затрат, исключению ошибок при передаче информации и полное исключение работы оператора по передаче данных о транспортном средстве для другого региона;

2) усовершенствовать существующий процесс. Например, за счет использования электронной почты наряду со служебным телефоном, что приведет к тому что уменьшится 
Перечень узких мест и связанные с ними риски

\begin{tabular}{|l|l|}
\hline \multicolumn{1}{|c|}{ Описание типового узкого места } & \multicolumn{1}{|c|}{ Потенциальные риски } \\
\hline \multicolumn{2}{|c|}{ Проблемы организационного уровня } \\
\hline 1) Основная деятельность ведется вручную & $\begin{array}{l}\text { 1) Временные затраты } \\
\text { 2) Возможность ошибки при ручном вводе }\end{array}$ \\
\hline \multicolumn{2}{|c|}{ Проблемы информационного уровня } \\
\hline $\begin{array}{l}\text { 1) Возможность ошибки при передаче } \\
\text { информации в устной форме }\end{array}$ & $\begin{array}{l}\text { 1) Возможность передачи ір адреса и номера } \\
\text { порта на другой сервер }\end{array}$ \\
\hline $\begin{array}{l}\text { 2) Возможность ошибки в понимании } \\
\text { речевой информации }\end{array}$ & $\begin{array}{l}\text { 1) Возможность ошибки при вводе ір адреса } \\
\text { и номера порта }\end{array}$ \\
\hline \multicolumn{2}{|c|}{ Проблемы технического уровня } \\
\hline $\begin{array}{l}\text { 1) Передача информации ведется через } \\
\text { служебный телефон }\end{array}$ & $\begin{array}{l}\text { 1) Возможность перехвата сигнала } \\
\text { 2) Возможность занятости служебного } \\
\text { телефона другим сотрудником } \\
\text { 3) Возможность отказа в форме «Линия занята» }\end{array}$ \\
\hline
\end{tabular}

вероятность ошибок при передаче данных с помощью почты, но возможно увеличатся временные затраты на процесс отправки и ожидания ответа от другого региона с помощью электронной почты. Также возможна полная замена использования служебного телефона на электронную почту, что в свою очередь приведет к значительному увеличению временных затрат на обработку передачу данных, так как оператор может не оперативно ответить на сообщение от другого оператора.

На основании анализа стратегий было принято решение реализовать первый способ оптимизации.

\section{Постановка задачи и проектирование модуля взаимодействия РНИС}

Приказ Минтранса РФ от 31 июля 2012 г. N 285 «Об утверждении требований к средствам навигации, функционирующим с использованием навигационных сигналов системы ГЛОНАСС или ГЛОНАСС/GPS и предназначенным для обязательного оснащения транспортных средств категории $\mathrm{M}$, используемых для коммерческих перевозок пассажиров, и категории $\mathrm{N}$, используемых для перевозки опасных грузов» [7] содержит общие требования к работе РНИС. При этом существует необходимость дополнительных требовании и данных для разработки модуля автоматизации. Так, к пакету данных о транс- портном средстве, который формировался и передавался изначально через абонентский терминал, расположенный на транспортном средстве, дополнительно необходимо обеспечить передачу следующего набора мониторинговой информации:

1) идентификационный номер геозоны;

2) ір адрес для перенаправления;

3) номер порта для перенаправления.

При выявлении требований к модулю, важно учитывать, что обмен данными между абонентским терминалом, системами и аппаратно-программными комплексами должен осуществляться при помощи сетей связи стандартов GSM и UMTS; время задержки поступления мониторинговой информации от навигационно-информационной системы к автоматизированному центру контроля и надзора Ространснадзора (АЦКН) - не более 60 секунд [8].

Информационная модель процесса передачи информации о транспортном средстве требуемому региону представлена на рис. 2.

В результате декомпозиции информационной модели ТО ВЕ были определены три процесса, характеризующие основной, - «Передача информации о транспортном средстве требуемому региону»:

1) процесс сбора информации о ТС - на данном этапе собирается пакет данных от абонентского терминала для отправки на сервер; 


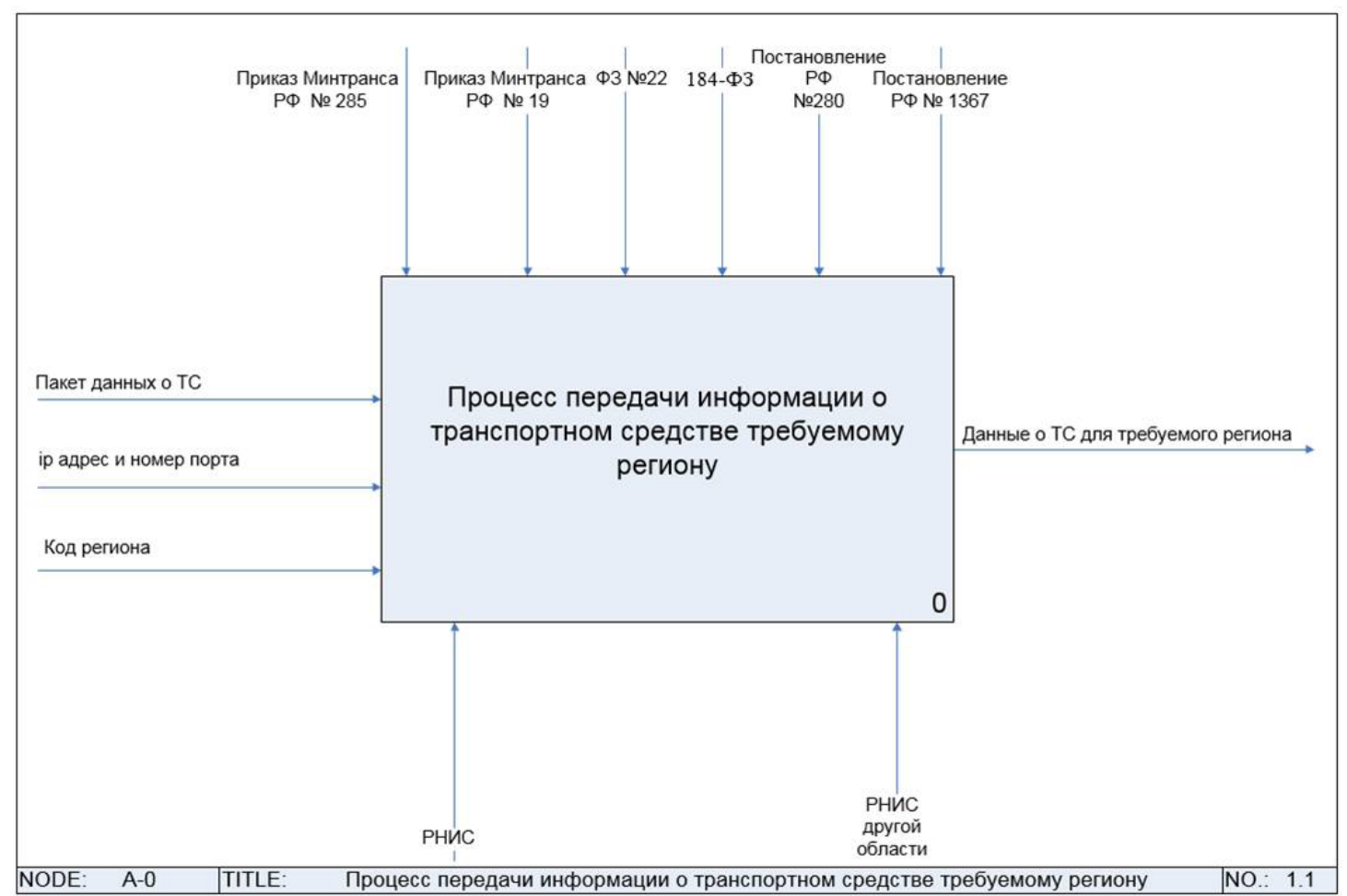

Рис. 2. Информационная модель процесса передачи инбормации о ТС (ТО ВE)

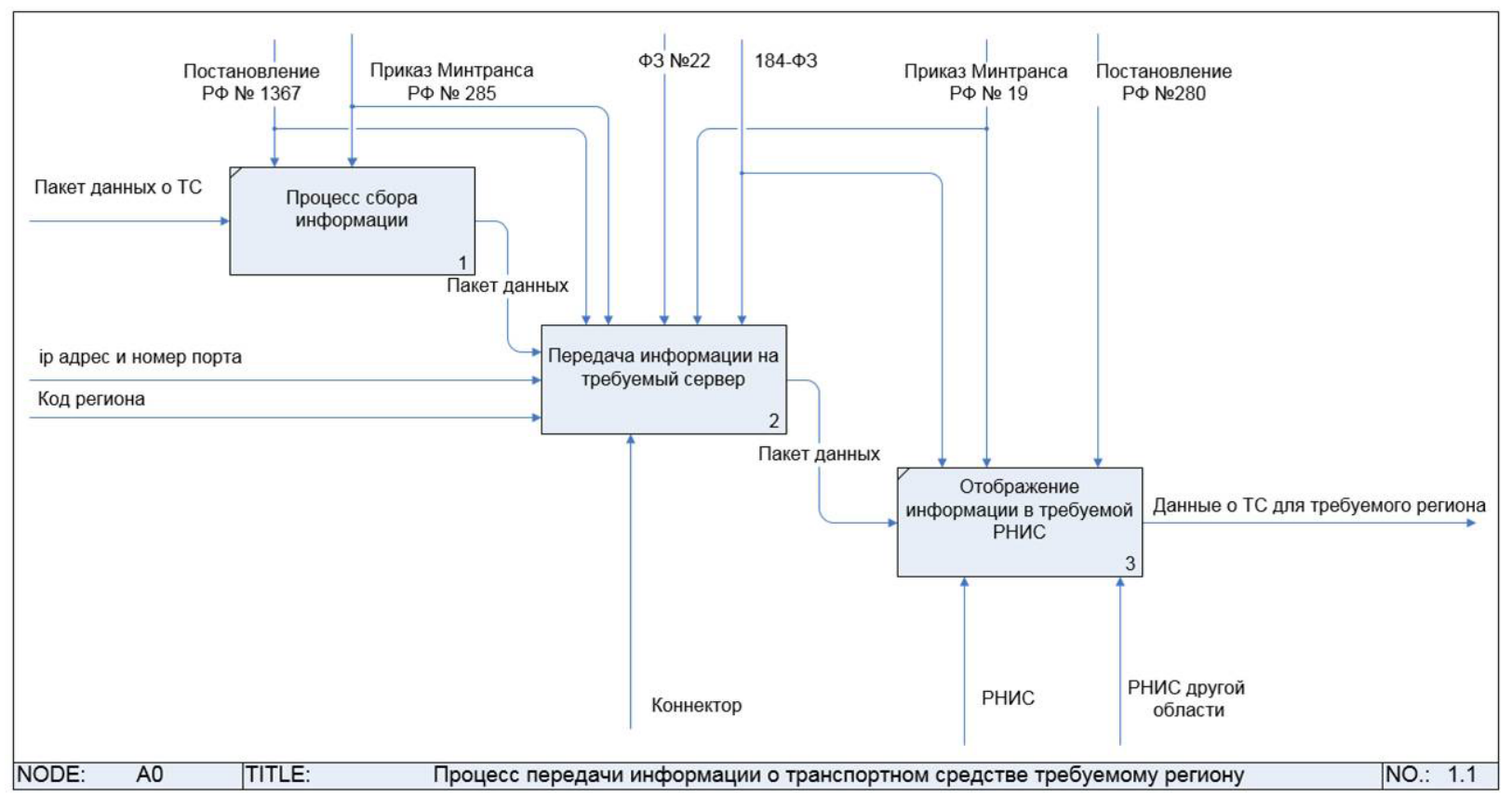

Рис. 3. Функциональная модель процесса передачи инбормации о транспортном средстве требуемому региону представлена (ТО ВE)

2) Передача информации на требуемый сервер - проверка необходимости передачи пакета данных на требуемый сервер (ближайший к текущему местоположению) где входными данными являются IP адрес, порт, код региона а так же пакет данных передающийся от абонентского терминала;
3) отображение информации в требуемой РНИС - пакет данных поступает для отображения и контроля в требуемую РНИС в форме, воспринимаемой оператором РНИС.

Функциональная модель процесса передачи информации о транспортном средстве требуемому региону представлена на рис. 3. 
Модель иллюстрирует то, что в процессе автоматизации удалось избавиться от работы оператора РНИС для процесса передачи данных о транспортном средстве для другого региона. Также было исключено дублирование информации с домашнего РНИС в РНИС другого региона. Данные передаются и обрабатываются с помощью ресурсов РНИС, на территории которой находится транспортное средство.

\section{Разработка модуля взаимодействия РНИС}

Для реализации модуля взаимодействия сетевая модель работы РНИС, включающая: сервер РНИС2 (сервер, используемый для хранения и обработки данных о проведенном медицинском осмотре водителей); web-сервер РНИС (основной сервер, хранящий информацию о транспортных средствах); сервер АРГО [8] (сервер на котором происходит преобразование протоков GPS в протоколы, поддерживаемые серверами РНИС); сервер телематики (сервер системы диспетчерского управления, который предназначен для сбора, обработки, хранения и маршрутизации мониторинговой информации от абонентских терминалов в диспетчерский центр);- дополнилась двумя справочниками: Справочник ір адресов и Справочник кодов регионов (рис. 4).
Для наглядного представления работы модуля была разработана интерфейсная часть (на языке программирования С\#), представленная на рис. 5.

Общую схему работы можно условно разделить на 4 этапа:

1) на первом этапе заполняется таблица данных о передвижении автомобилей: вносятся значения id, $\mathrm{x}, \mathrm{y}$ и нажатием кнопки добавляется строка. Данное действие возможно путем нажатия кнопки, добавляющей новые случайные значения в таблицу («Добавить следующее случайное значение»). Новые данные отображаются в верней части области «Таблица Car».

2) вторым этапом идет автоматическая сверка новых данных с таблицей Nreg («Taблица с номерами регионов») и из этой таблицы выбирается строка, где находятся такие же координаты, что и у таблицы Car, и из этой строки выбирается значение Nreg (номер региона).

3) далее из другой таблицы, хранящей iр адреса и номера портов регионов (SeverAndPort) выбирается строка с выбранным ранее значением поля Nreg, а из этой строки в систему поступают значения (IpServer и Port), необходимые для подключения к требуемому серверу РНИЦ.

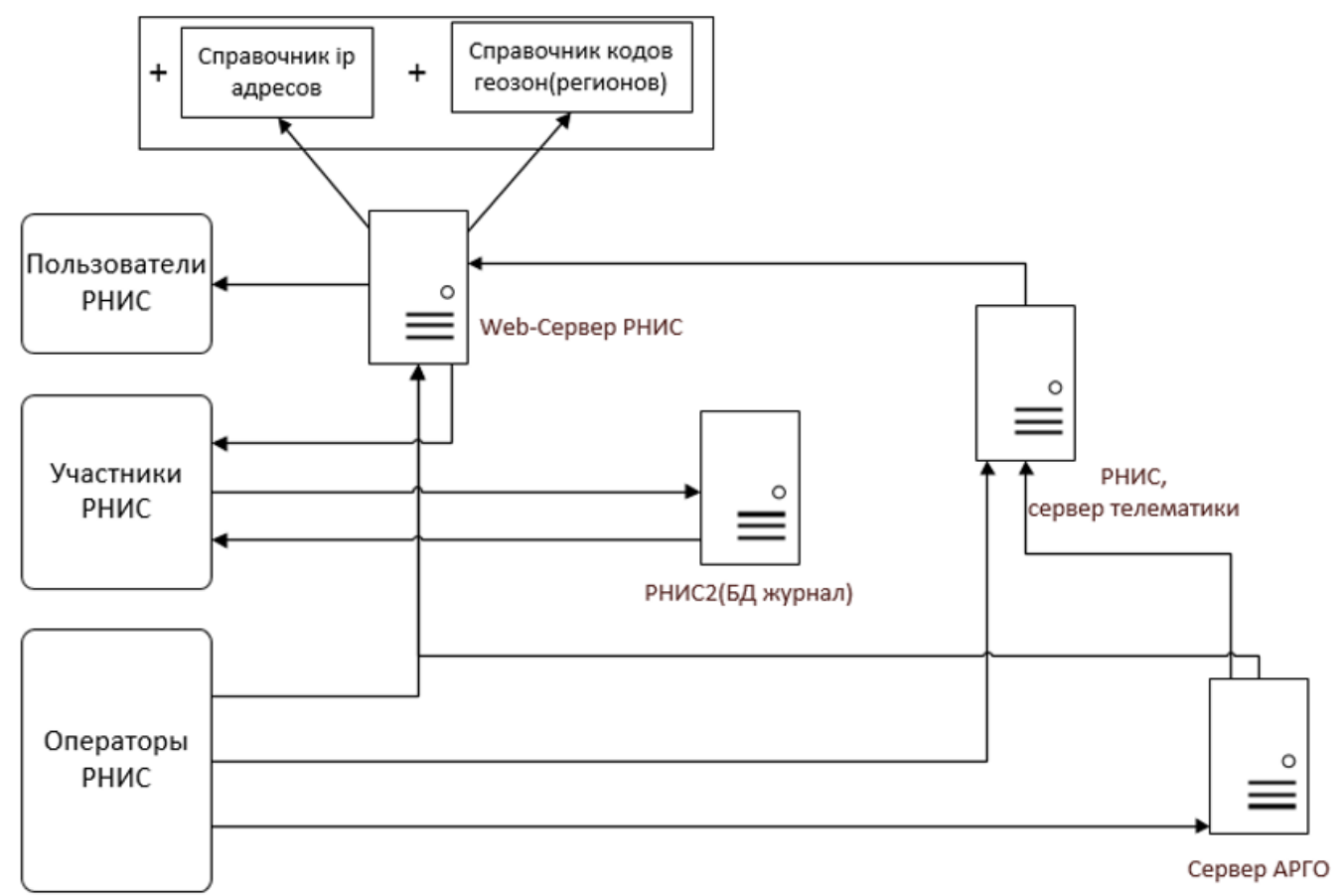

Рис. 4. Сетевая модель РНИС 


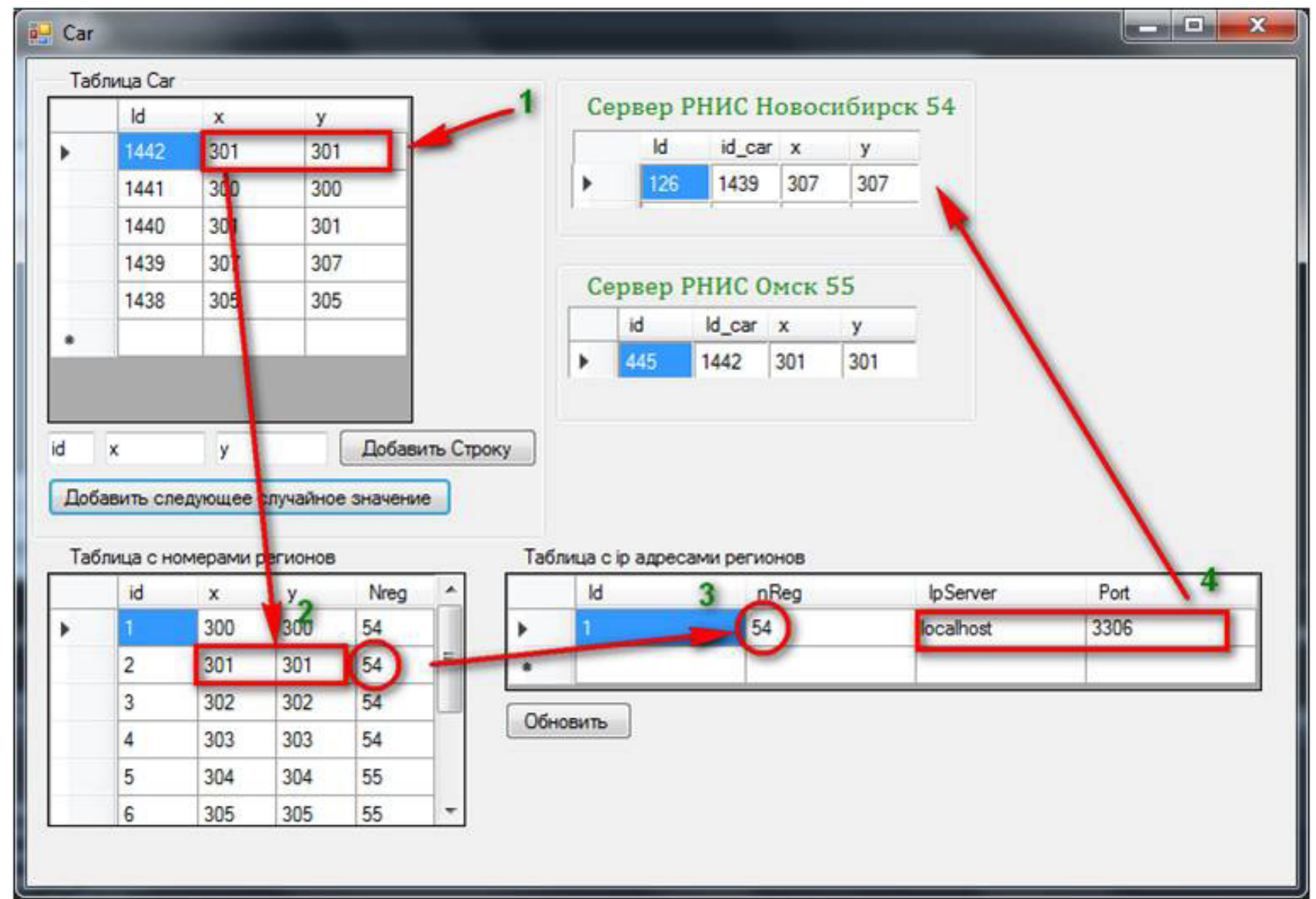

Рис. 5. Схема работы модуля

4) на четвертом этапе данные поступают на нужный сервер РНИЦ и отображаются в РНИС.

\section{ЗАКЛЮЧЕНИЕ}

Таким образом, в результате исследования существующего процесса оповещения РНИС другой области о необходимости контроля за транспортным средством, находящемся в зоне видимости, была обоснована необходимость автоматизации данного процесса; разработан модуль взаимодействия региональных навигационно-информационных систем. Внедрение модуля взаимодействия РНИС позволит реализовывать заданный функционировал без участия пользователей (операторов РНИС), автоматически перенаправлять пакет данных от транспортного средства к требуемой РНИС.

\section{СПИСОК ЛИТЕРАТУРЫ}

1. Власов, В. М. Методические подходы к созданию и развитию региональных навигационно-информационных систем диспетчерского управления, безопасности и информирования на наземном транспорте / В. М. Власов // Автотранспортное предприятие. - 2014. - № 6. C. 6-8.

2. Питиримов, А. В. Вопросы создания региональной навигационно-информационной системы (РНИС) Псковской области / А. В. Питиримов // ГЛОНАСС - Регионам: материалы 3-ей Всероссийской научно-практической конференции ФГБОУ ВПО «Госуниверситет - УНПК», под общей редакцией д.т.н., проф. А. Н. Новикова. - Орел, 2013. C. $18-21$.

3. Воронина, М. А. Основные приоритеты региональной целевой программы внедрения технологий ГЛОНАСС в Орловской области / М. А. Воронина, С. А. Алимов // Фундаментальные научные исследования: сборник материа- 
лов VII Международной научно-практической конференции. - Кемерово, 2018. - С. 56-58.

4. О государственной информационной системе Омской области «Региональная навигационно-информационная система Омской области». Распоряжение Губернатора Омской области от 30 апреля 2015 года N 95-p // Официальный интернет-портал правовой информации. Режим доступа: http://publication. pravo.gov.ru. - дата опубликования: 30.04.2015.

5. Юрьева, В. Н. Архитектурное решение информационного взаимодействия между перевозчиками и Региональной навигационно-информационной системой Правительства Омской области / В. Н. Юрьева, Л. И. Остринская // Архитектурно-строительный и дорожно-транспортный комплексы: проблемы, перспективы, инновации: сборник материалов II Международной научно-практической конференции. Сибирский государственный автомобильно-дорожный университет (СибАДИ). Омск, 2017. - С. 327-333.

6. Инжиниринг и проектирование информационных систем для объектов автоматизации: анализ проблем, практика решений. Проектирование информационных процессов обработки документов при взаимодействии автоперевозчиков с Региональной навигационно-информационной системой Правительства Омской области: отчет о НИР (промежуточный): 15-2С / СибАДИ; рук. Остринская Л. И., исполн.: Остринская Л. И.,

Остринская Любовь Ивановна - канд. экон. наук, декан факультета «Информационные системы в управлении», заведующий кафедрой «Прикладная информатика в экономике», ФГБОУ ВО СибАДИ.

Тел.: 8(3812)60-55-50

E-mail:1_i_romanova@mail.ru

Пестова Светлана Юрьевна - канд. пед. наук, доцент кафедры «Прикладная информатика в экономике», ФГБОУ ВО СибАДИ.

Тел.: 8(3812)60-55-50

E-mail: pestova_sv@mail.ru
Пестова С. Ю., Ключенко А. А., Юрьева В. Н. Омск, 2017. - 70 с. - № ГР 116012010023 № Инв. АААА-Б17-217011040090-1

7. Об утверждении требований к средствам навигации, функционирующим с использованием навигационных сигналов системы ГЛОНАСС или ГЛОНАСС/GPS и предназначенным для обязательного оснащения транспортных средств категории $\mathrm{M}$, используемых для коммерческих перевозок пассажиров, и категории $\mathrm{N}$, используемых для перевозки опасных грузов. Приказ Минтранса РФ N 285 [Принят 31 июля 2012 года]. - Режим доступа: http://www.garant.ru/ products/ipo/prime/doc/70129002/ - (Дата обращения: 27.010.2018).

8. Об утверждении Порядка оснащения транспортных средств, находящихся в эксплуатации, включая специальные транспортные средства, категории М, используемых для коммерческих перевозок пассажиров, и категории $\mathrm{N}$, используемых для перевозки опасных грузов, аппаратурой спутниковой навигации ГЛОНАСС или ГЛОНАCС/GPS”. Приказ Минтранса РФ № 20 от 26 января 2012 г. Режим доступа: http://www.garant.ru/products/ ipo/prime/doc/70041388/\#ixzz5Wcea9bqs (Дата обращения: 07.11.2018).

9. АРГО - система мониторинга коммерческого транспорта. - Режим доступа: http:// rnic55.ru/1_MT_RU.pdf - (Дата обращения: 04.11.2018).

Ostrinskaya Liubov Ivanovna - candidate of Economic Sciences, Dean of the faculty «Information systems in management», associate Professor, head of the Department of «Applied Informatics in Economics», SibADI.

Tel.: 8(3812)60-55-50

E-mail:1_i_romanova@mail.ru

Pestova Svetlana Yurievna - candidate of Pedagogic Sciences, associate Professor of the Department of "Applied Informatics in Economics», SibADI.

Tel.: 8(3812)60-55-50

E-mail: pestova_sv@mail.ru 
Козлова Алена Васильевна - старший пре- Kozlova Alena Vasilievna - Senior Lecturer of подаватель кафедры «Прикладная информатика в экономике», ФГБОУ ВО СибАДИ. the Department of «Applied Informatics in EcoТел.: 8(3812)60-55-50 nomics», SibADI.

E-mail: kozlova.av@mail.ru Tel.: 8(3812)60-55-50

E-mail: kozlova.av@mail.ru

Ключенко Андрей Александрович - заместитель начальника, Главное управление информационных технологий и связи Омской области.

Klyuchenko Andrey Aleksandrovich - Deputy Head, General Directorate of Information Technologies and Communications of the Omsk Region.

Тел.: 8(3812)77-04-77

Tel.: 8(3812)77-04-77

E-mail: post@guit.omskportal.ru

E-mail: post@guit.omskportal.ru 